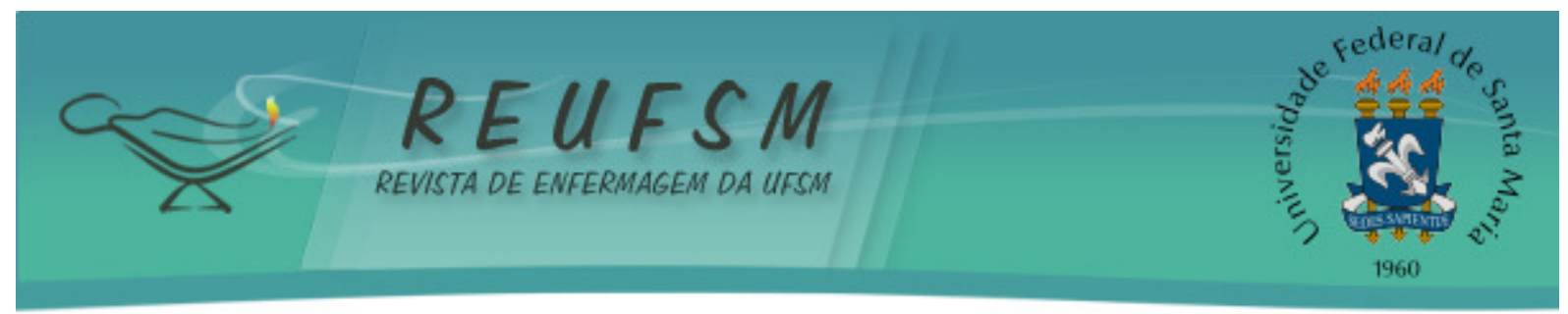

ARTIGO ORIGINAL

\title{
TRATAMENTO EM LIBERDADE: PONTOS DE TENSIONAMENTO E AVANÇO NO CENTRO DE ATENÇÃO PSICOSSOCIAL
}

\section{TREATMENT IN FREEDOM: POINTS OF TENSIONING AND ADVANCE IN A PSYCHOSOCIAL CARE CENTER}

\section{TRATAMIENTO EN LIBERTAD: PUNTOS DE TENSIÓN Y DE ADELANTO EN EL TRABAJO DENTRO DEL CAPS}

\author{
Ariane da Cruz Guedes ${ }^{1}$ \\ Luciane Prado Kantorski ${ }^{2}$ \\ Valéria Cristina Christello Coimbra ${ }^{3}$ \\ Agnes Olschowsky ${ }^{4}$ \\ Jandro Moraes Cortes ${ }^{5}$ \\ Karen Jeanne Cantarelli ${ }^{6}$
}

Doi: $10.5902 / 217976928931$

RESUMO: Objetivo: conhecer os tensionamentos e avanços do tratamento em liberdade em um Centro de Atenção Psicossocial (CAPS), sob a visão dos usuários do serviço. Método: estudo exploratório e descritivo, com abordagem metodológica qualitativa, sendo um recorte da pesquisa "Avaliação dos CAPS da região sul do Brasil (CAPSUL)". A coleta de dados foi desenvolvida por três pesquisadores em um CAPS II no município de Alegrete-RS, no segundo semestre de 2006. Foram realizadas entrevistas semiestruturadas com 11 usuários. Resultados: identificaram-se quatro temáticas: os avanços no tratamento em liberdade; as estratégias para a reinserção social; o reposicionamento do usuário enquanto cidadão e os nós críticos do tratamento em liberdade. Considerações finais: por meio dos depoimentos dos participantes, percebe-se que o CAPS investe em estratégias que promovem a reinserção social dos usuários, o que contribui significativamente para que o tratamento em saúde mental seja em liberdade, fortalecendo assim o reposicionamento do usuário enquanto cidadão.

Descritores: Saúde mental; Serviços de saúde mental; Desinstitucionalização.

ABSTRACT: Aim: knowing the tensioning and advances of the treatment in freedom in a Psychosocial Attention Center (PAC), under the vision of the users of the service. Method: exploratory and descriptive study, with qualitative methodological approach, an extract from the research Evaluation of the PAC in the South of Brazil. The data collection was developed by three researchers in one PACII in the city Alegrete-RS, in the second semester of 2006. Semi-structured interviews were done with 11 users. Results: four themes were identified: advance in the treatment with freedom; the strategies for social reinsertion; the user's repositioning as citizen and the critical knots of the treatment in

\footnotetext{
${ }^{1}$ Enfermeira. Mestre em Ciências pelo Programa de Pós-Graduação em Enfermagem da Universidade Federal de Pelotas. Doutoranda em Enfermagem do Programa de Pós-Graduação em Enfermagem da Universidade Federal do Rio Grande do Sul. Porto Alegre-RS. Brasil. Email: arianecguedes@gmail.com

${ }^{2}$ Enfermeira. Doutora em Enfermagem Psiquiátrica pela Universidade de São Paulo. Docente da Faculdade de Enfermagem da Universidade Federal de Pelotas. Pelotas-RS. Brasil. Email: kantorski@uol.com.br

${ }^{3}$ Enfermeira. Doutora em Enfermagem Psiquiátrica pela Universidade de São Paulo. Docente da Faculdade de Enfermagem da Universidade Federal de Pelotas. Pelotas-RS. Brasil. Email: valeriacoimbra@hotmail.com

${ }^{4}$ Enfermeira. Doutora em Enfermagem Psiquiátrica pela Universidade de São Paulo. Docente da Escola de Enfermagem da Universidade Federal do Rio Grande do Sul. Porto Alegre-RS. Brasil. Email: agnes@enf.ufrgs.br

${ }^{5}$ Enfermeiro. Doutorando pelo Programa Interunidades em Enfermagem da Escola de Enfermagem da Universidade de São Paulo. São Paulo-SP. Brasil. Email: jandromcortes@hotmail.com

${ }^{6}$ Enfermeira. Mestranda pelo Programa de Pós-Graduação em Enfermagem da Universidade Federal do Rio Grande do Sul. Porto Alegre-RS. Brasil. Email: kjcantarelli@yahoo.com.br
} 


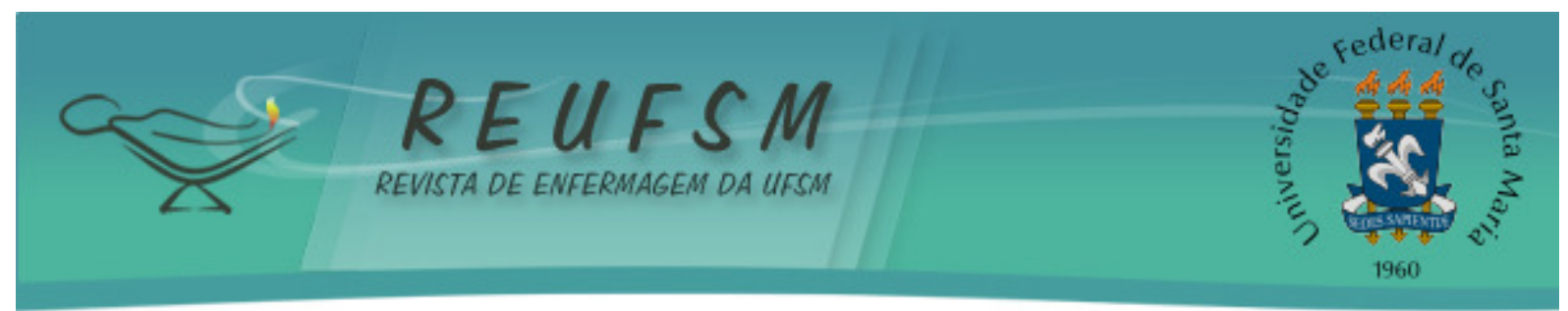

freedom. Final considerations: through the participants, it is perceived that PAC invests in strategies that promote the social reinsertion of the users, which contributes significantly so that the treatment in mental health is with freedom, strenghtening the repositioning of the user as citizen.

Descriptors: Mental health; Mental health services; Deinstitutionalization.

RESUMEN: Objetivo: conocer las tensiones y avances del tratamiento en libertad en un Centro de Atención Psicosocial (CAPS), bajo la visión de los usuarios del servicio. Método: estudio exploratorio, descriptivo y cualitativo, siendo un recorte de la investigación de Evaluación de CAPS de la Región Sur de Brasil (CAPSUL). La recogida de datos fue desarrollada por tres investigadores del CAPS II en Alegrete-RS, durante el segundo semestre de 2006. Fueron realizadas entrevistas semiestructuradas con 11 usuarios. Resultados: se identificaron cuatro temáticas: los avances en el tratamiento en libertad; estrategias para la reintegración social; reposicionamiento del usuario como ciudadano y nudos críticos del tratamiento en libertad. Consideraciones finales: por medio de testimonios de los participantes, se percibe que el CAPS invierte en estrategias que promueven la restitución social de los usuarios, que contribuye significativamente para que el tratamiento en la salud mental ocurra en libertad, fortaleciendo el reposicionamiento del usuario como ciudadano.

Descriptores: Salud mental; Servicios de salud mental; Desinstituicionalización.

\section{INTRODUÇÃO}

0 presente estudo se insere nas temáticas que pretendem estudar e investigar as práticas em saúde mental desenvolvidas no contexto da atenção psicossocial, no cenário dos Centros de Atenção Psicossocial (CAPS), e que contribuem para a consolidação do processo de reforma psiquiátrica.

A reforma no Brasil teve seu início em fins da década de setenta, surgindo num contexto de transformação das políticas de saúde em geral. Sendo assim, constitui-se em um movimento recente, o qual é marcado por muitas lutas e reinvidicações por parte dos trabalhadores dos serviços de saúde mental, usuários e seus familiares. Seu principal objetivo é a reestruturação da assistência psiquiátrica, substituindo o modelo médico-centrado e segregador quando o cuidado era fundamentalmente baseado na doença e não no indivíduo.

Nesse contexto surgiram os CAPS, estabelecidos por meio da Portaria 336 de 19 de fevereiro de 2002. ${ }^{1}$ Estes se constituem em serviços substitutivos ao modelo hospitalocêntrico, de base comunitária e ambulatorial, que tomam para si a responsabilidade de cuidar de pessoas que sofrem com transtornos mentais, em especial, os transtornos severos e persistentes no seu território de abrangência. Devem garantir relações entre trabalhadores e usuários centradas no acolhimento e no vínculo, incluindo também ações voltadas aos familiares. São compromissados na construção de projetos de inserção social, os quais minimizem o estigma e promovam melhor qualidade de vida e inclusão social possíveis. ${ }^{2}$

$\mathrm{O}$ atendimento fundamentado no modo psicossocial, especialmente nos CAPS, possibilita que os usuários se (re)insiram na sociedade e também participem de diferentes ações sociais que não eram permitidas com o atendimento pautado pela institucionalização em manicômios. ${ }^{3}$

Anteriormente, quando a atenção em saúde mental era realizada exclusivamente em hospitais psiquiátricos, os indivíduos com transtornos mentais eram vistos como seres sem direitos e deveres, tendo o diagnóstico psiquiátrico como principal rótulo de definição. Portanto, no contexto atual é necessário que se invista em iniciativas de reabilitação psicossocial, autonomia e reinserção social, para que os usuários reconquistem suas potencialidades de vida. 


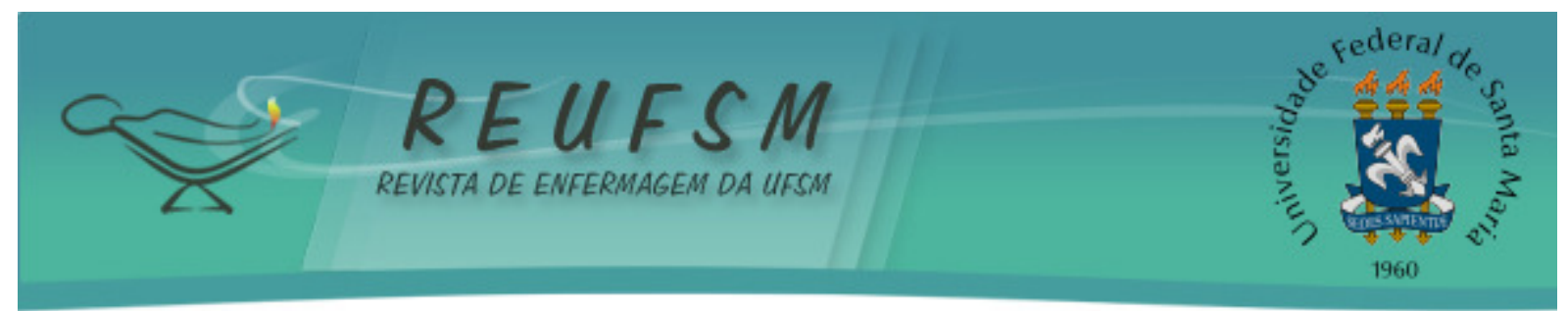

A construção da plena cidadania é o ponto fundamental da reabilitação psicossocial e esta depende de variáveis que operam contra, ou operam a favor da contratualidade em casa, no trabalho e na rede social. ${ }^{4} \mathrm{E}$ é através desse poder contratual exercido pelo sujeito que se inicia a trilha por um caminho que dá sentido à vida, um caminho livre, sem preconceitos e acima de tudo, da ressignificação da identidade de quem tem o direito de construir a sua própria história.

E nesta nova configuração de assistência em saúde mental, surgem tensionamentos e avanços nos serviços, os quais estão em constantes transformações, na medida em que novas experiências e práticas são reformuladas e reinventadas.

Compreende-se que os usuários são os principais protagonistas neste cenário, de transformação de saberes e práticas. Portanto, objetivou-se por meio deste artigo conhecer os tensionamentos e avanços do tratamento em liberdade em um Centro de Atenção Psicossocial (CAPS), sob a visão dos usuários do serviço.

\section{MÉTODO}

Trata-se de um estudo de caráter exploratório e descritivo, com abordagem metodológica qualitativa. Foi analisado, a partir de um recorte da pesquisa "Avaliação dos Centros de Atenção Psicossocial da Região Sul do Brasil (CAPSUL)".

O estudo foi desenvolvido no contexto de um CAPS II do município de Alegrete, Rio Grande do Sul, durante o segundo semestre do ano de 2006. Participaram da coleta de dados três pesquisadores previamente capacitados.

Os sujeitos participantes do estudo constituíram-se em 11 usuários do serviço. A fim de garantir o anonimato da identidade destes, os mesmos foram identificados pela ordem em que foram entrevistados (ex.: Ent. 1; Ent. 2).

Para participar do estudo, os sujeitos seguiram os seguintes critérios: que frequentassem o serviço há mais de seis meses; tivessem boas condições de comunicação no momento, ou seja, que não estivessem em crise psicótica ou desorientação no tempo e no espaço; bom vínculo com o serviço, vínculo ruim ou sem aderência; que já tivessem frequentado ou frequentassem o serviço na modalidade intensiva ou semi-intensiva.

Para a coleta dos dados, foram utilizadas entrevistas semiestruturadas, as quais foram gravadas em áudio e transcritas na íntegra.

A análise dos dados foi realizada por meio da análise temática ${ }^{5}$, desdobrando-se em três etapas: pré-análise; exploração do material; e tratamento dos dados obtidos e interpretação. Como resultados foram identificadas quatro categorias analíticas, após a tematização das entrevistas.

Os direitos éticos foram assegurados de acordo com a Resolução $n^{\circ}$ 196/96 do Conselho Nacional de Saúde, do Ministério da Saúde. ${ }^{6}$ Este estudo foi aprovado pelo Comitê de Ética da Faculdade de Medicina da Universidade Federal de Pelotas, sob o ofício de número 074/05.

\section{RESULTADOS E DISCUSSÃO}

Por meio da análise dos dados, puderam ser identificadas quatro temáticas: os avanços no tratamento em liberdade; as estratégias do CAPS para a reinserção social; o reposicionamento do usuário enquanto cidadão e nós críticos do tratamento em liberdade. Estas serão destacadas a seguir:

\section{Os avanços no tratamento em liberdade}

Constataram-se no trabalho realizado no contexto do CAPS do município de Alegrete, diversas ações comprometidas com a liberdade, identificadas pelos principais atores desse âmbito: os usuários do serviço. Um dos avanços no tratamento em liberdade 


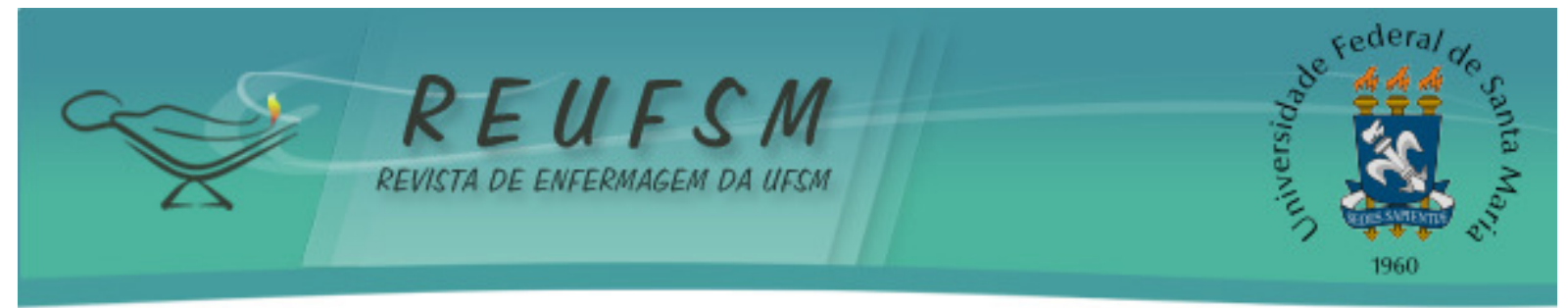

compreendido no contexto do CAPS de Alegrete é o atendimento ao usuário em situações de crise, sendo suporte e acolhimento neste momento.

Para compreensão, vale ressaltar que a palavra crise provém do grego krísis, a qual significava, na sua origem, momento de mudança súbita, de decisão; julgar, separar, decidir. Já na história da medicina, segundo remotas concepções, a crise constituía um momento crucial para evolução de uma doença, para cura ou para morte. E para os chineses se constitui, ao mesmo tempo, oportunidade e risco. ${ }^{7}$

Nesse sentido, a crise é entendida como resultado de uma série de fatores que envolvem terceiros como familiares, amigos, vizinhos ou até mesmo desconhecidos. Esse momento pode ser resultado de uma diminuição do limiar de solidariedade bem como de tolerância de uns com os outros. Consiste numa situação de precariedade de recursos para tratar o indivíduo em sua residência. Por isso, pelo fato de tratar-se de um processo social constitui-se numa situação mais social que puramente psicológica ou biológica. ${ }^{8}$

Em relação a esse fato, se percebe no serviço o envolvimento com os indivíduos, pois no momento em que o usuário carece de atendimento, qualquer dia e independentemente da hora, a equipe desloca-se até o domicílio deste e o encaminha ao Pronto Atendimento especializado, acompanhando o sujeito em todo o processo do sofrimento:

Então hoje se a gente precisa de um atendimento, seja a hora que for, a gente sempre tem o número de alguém para ligar. Se precisarem de internação eles vão a casa, eles pegam a pessoa, tem leito disponível no hospital. (Ent. 7)

Tratando-se de crises psíquicas, o desespero, o desarranjo, as vozes, visões ou a eclosão psicótica traduzem também uma tentativa de resolução de problemas e sofrimentos importantes ou de cura. Em saúde mental, os sintomas não essencialmente devem ser suprimidos, muitas vezes eles devem ser suportados e acolhidos. ${ }^{7}$ Sendo assim, o CAPS de Alegrete promove o acolhimento ao usuário neste momento importante de sua existência.

A desinstitucionalização abrange não somente a desconstrução do manicômio, mas ainda a desconstrução de saberes e estratégias, ancorados em uma assistência pautada na noção existência-sofrimento do usuário e sua relação em sua rede social. $E$ isto remete a um problema de cidadania e ética, na noção básica do processo de reabilitação psicossocial. ${ }^{9}$

$\mathrm{Na}$ fala a seguir, o usuário faz um paralelo da atenção dispensada no hospital psiquiátrico, referindo discriminação e preconceito, e distingui da atenção psicossocial que recebe no CAPS:

A discriminação antes era assim, tratavam que nem bicho, levavam... a primeira coisa era atar as pessoas, aquelas cenas horrorosas, e agora a gente já não vê mais isso. Eu acho ótimo o atendimento. (Ent. 7)

No depoimento anterior, percebe-se que o usuário identificou diferenças no atendimento, fazendo um paralelo com os dois modelos distintos: o hospitalocêntrico e o da atenção psicossocial. Para que um serviço de saúde mental seja efetivo neste novo modelo assistencial, é necessário que esteja em constante reflexão e aprimoramento, para que as ações retrógradas não continuem sendo reproduzidas.

Não basta transformar os locais de atendimento se não forem transformadas as representações agregadas à doença mental, promovendo um movimento que dissocie a loucura da improdutividade, da incapacidade de articulação social e da violência. Sendo assim, o movimento de reforma psiquiátrica traz conceitos inovadores e complexos, alterando o foco de atenção da doença para o sujeito, tendo como objetivo o atendimento em equipe interdisciplinar. ${ }^{10}$ 


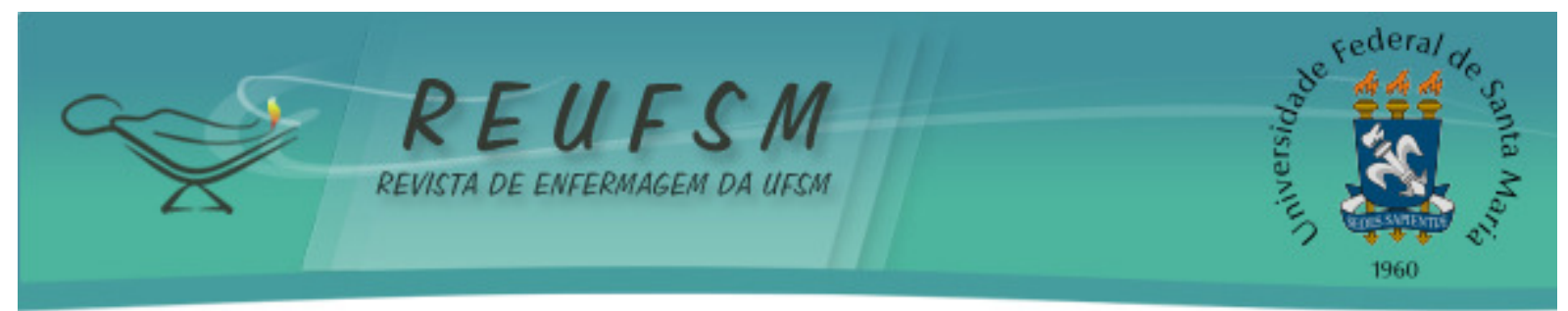

E para que sejam modificadas as ações em saúde mental, é necessário que todo trabalho realizado no CAPS esteja inserido em meio terapêutico, isto é, tanto as sessões individuais ou grupais como a convivência no serviço devem ter finalidade terapêutica. Esse objetivo é alcançado através da construção permanente de um ambiente facilitador, estruturado e acolhedor, abrangendo várias modalidades de tratamento. O CAPS deve articular cuidado clínico e programas de reabilitação psicossocial. ${ }^{11}$

Por meio da recomendação do Ministério da Saúde, destacada anteriormente, percebe-se o comprometimento que os CAPS devem ter em relação à dispensação de cuidados em seu interior, pois apesar de preocupar-se com o tratamento em liberdade, deve fornecer programas de reabilitação social, e todas as atividades realizadas necessariamente devem ter cunho terapêutico.

Nesse contexto, há outra verbalização que explicita a correlação que os usuários fazem entre o tratamento dispensado no CAPS e a liberdade conquistada por eles nesse serviço. No depoimento a seguir, o indivíduo destaca o fato de muitos usuários do serviço terem vivenciado previamente experiências dentro do manicômio, mas que neste novo contexto de assistência em saúde mental se apropriaram da liberdade:

Só em ver a liberdade deles, que eles têm aí... muitos conviveram no manicômio, viveram no manicômio, aquela minha tia mesmo viveu num manicômio, só de eles terem liberdade deles, já é grande ganho para eles. (Ent. 9)

Assim, o CAPS é compreendido como um serviço potente, norteador na promoção de transformações nos campos técnico-assistencial e teórico-conceitual, nos quais a pluralidade e a singularidade são fundamentais na superação do conceito de cura, de desvio, de classificação, de periculosidade da loucura e de incapacidade. Desmitificar preconceitos que aprisionam histórias de vida e sujeitos traduz-se em um desafio, e requer o reconhecimento do indivíduo em sofrimento psíquico como tal, estimando-o como alguém que faz e pode. Um sujeito social, capaz de produzir conhecimentos, de estabelecer trocas e laços de solidariedade e afeto. ${ }^{12}$

Cada dia que passa, eu cresço, porque eu saio na sociedade e me sinto grande, me sinto uma pessoa fortalecida. $E$ todos os serviços que eu faço aqui dentro do serviço da saúde mental para mim é motivo, parece que eu cresço. (Ent. 2)

No depoimento anterior, percebe-se que o CAPS cumpre o seu papel de promoção da reabilitação psicossocial dos usuários, pois estes referem que se sentem fortalecidos para atuar no cenário social.

Ainda neste foco, um serviço psiquiátrico só será de alta qualidade a partir do momento em que garantir programas reabilitadores confiáveis, sendo que a boa qualidade não remete, necessariamente, a quantidade de recursos disponíveis e nem ao menos quanto à qualidade das tecnologias terapêuticas utilizadas. Esse serviço idealizado se tornará de alta qualidade quando se ocupar de todos os pacientes que o procuram, ao mesmo tempo em que oferecer reabilitação a todos que possam se beneficiar dela. ${ }^{13}$

Se não fosse o serviço me dava uma tristeza, nem sei o que seria de mim. Aqui eu me levantei, saí daquela depressão, agora estou bem, me sentindo bem melhor, me sentindo outra pessoa com a ajuda do serviço. Tanto o serviço como meus familiares, agora eu estou outra pessoa, bem ativa. (Ent. 6) 


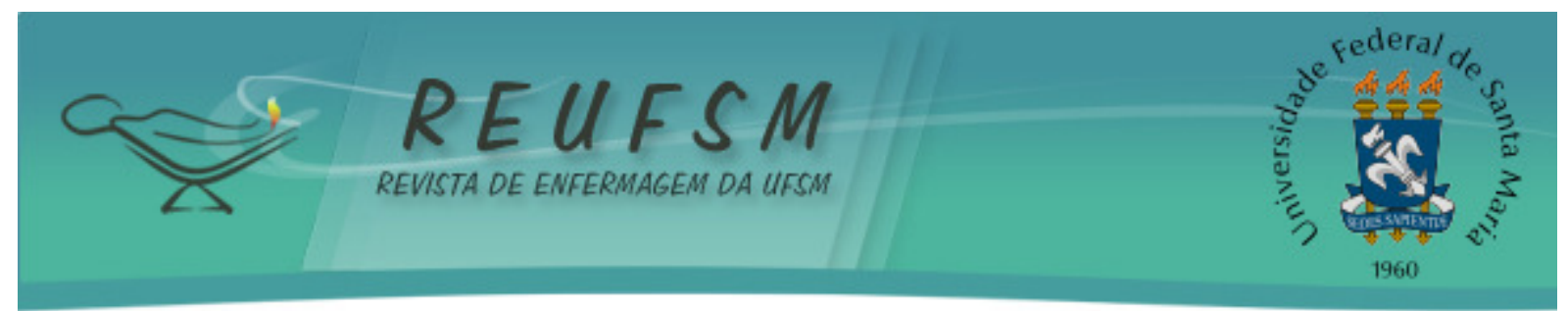

A reabilitação psicossocial é um conjunto de atividades aptas para oferecer condições amplas de recuperação dos sujeitos, através da utilização de recursos familiares, individuais e comunitários, a fim de neutralizar os efeitos cronificadores e iatrogênicos da doença. A reabilitação em si, significa auxiliar o indivíduo em sofrimento psíquico a ultrapassar suas limitações e incapacidades e promover o auto-cuidado, com o objetivo de elevar-lhe a autoestima, oportunizando a restituição da identidade social, pessoal e sua autonomia. ${ }^{6}$

Em muitos momentos o CAPS torna-se estratégico na vida do usuário, para que esse consiga enfrentar suas limitações, para que se sinta motivado a lutar em favor da sua vida. Nas citações a seguir exemplifica-se claramente essa afirmação, pois o serviço foi de fundamental importância para a estruturação de vida do usuário:

Nesse tempo que eu estou em tratamento, é o que me estruturou de novo para enfrentar a vida, nesse momento foi tudo para mim. Porque se não tivesse isso aqui, eu estaria me entupindo de medicação... só isso! [...] Isso aqui foi tudo. (Ent. 7)

Outra pessoa... me sinto muito bem, me sinto alegre, descontraída. Estou super calma, tranquila, coisa que eu não sou, porque eu sou agitada, então me sinto super legal mesmo. (Ent. 5)

Através da análise dessa temática ressalta-se que o CAPS do município de Alegrete está exercendo seu papel de facilitador na vida do usuário, tem cumprido seu objetivo em fornecer suporte aos indivíduos, sem ser meramente assistencialista, mas contribuinte para que o sujeito em sofrimento psíquico consiga alcançar sua independência social e autonomia.

\section{As estratégias do CAPS para a reinserção social}

O objetivo do CAPS é oferecer atendimento territorializado à população de sua área de abrangência, desempenhando acompanhamento clínico e reinserção social dos usuários pelo acesso ao exercício dos direitos civis, trabalho, lazer, e fortalecimento dos laços comunitários e familiares. ${ }^{11}$

No discurso a seguir o usuário afirma o resultado obtido com o tratamento no CAPS, refere o fato que está usufruindo a vida de maneira "normal", realmente inserido em seu contexto social:

Depois que eu estou fazendo esse tratamento aqui dentro do CAPS com acompanhamento médico, psicóloga, enfermeiros, toda a minha vida está sendo normal [...] levo a minha vida normal, fazendo as minhas coisas de dona de casa, vou ao mercado, ao banco, recebo meu beneficio, tudo eu faço [...] estou sentindo que eu voltei a ser o que eu era antes. (Ent. 10)

Um outro aspecto importante a ser observado é em relação às atividades oferecidas ao usuário. Estas devem ter cunho terapêutico visando, sobretudo, a interação entre usuários e equipe, bem como o estreitamento dos vínculos. E nesse sentido há a oportunidade em transformar atividades terapêuticas em momentos que proporcionem a reinserção do usuário na sociedade. Na verbalização abaixo, o Ent. 1 afirma participar de diversas atividades dentro do serviço e percebe-se que, com isso, há uma integração social: 


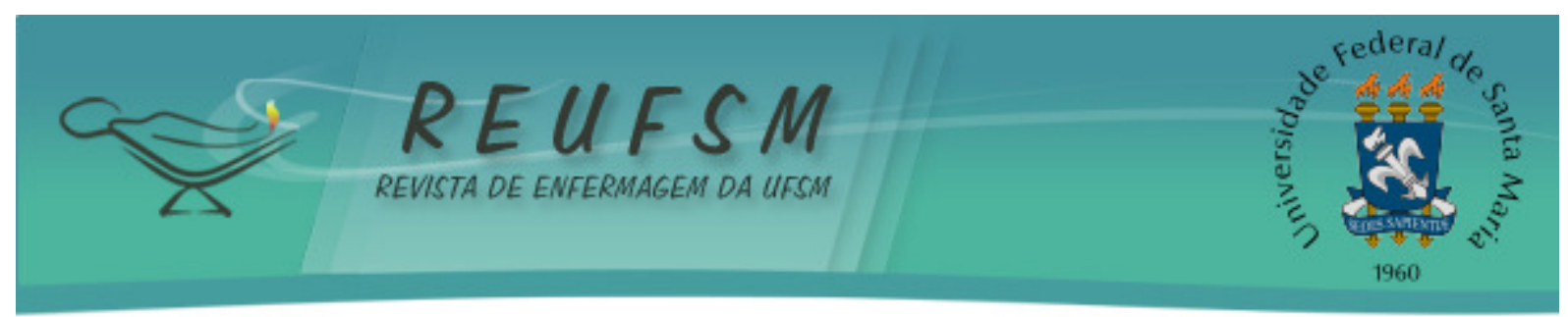

Eu faço aula de capoeira, educação física, reiki, aula de judô, jogo futebol, aqui no serviço às vezes fiz um torneiozinho de futebol, caminhamos, atividade física tem bastante, fazemos algumas atividades físicas, eu acho excelente o serviço de saúde física aqui. (Ent. 1)

As oficinas terapêuticas são atividades que permitem o encontro do indivíduo em sofrimento psíquico, promovendo assim, o exercício da sua cidadania, a demonstração de sua liberdade e convivência dos diferentes. Essas surgiram no decorrer do processo histórico da psiquiatria, porém com um objetivo diferente do referencial do paradigma psicossocial. Presentemente se constituem a partir de princípios específicos, ou seja, através da reinserção de sujeitos em sofrimento psíquico na sociedade, sobretudo respeitando a singularidade, peculiaridades e regionalidades de cada um deles. ${ }^{14} \mathrm{~A}$ fala a seguir confirma o que o autor defende:

Eu faço tapete, eu pinto, tenho que terminar meu tapete. Fiar um tapete bonito, do Inter [time de futebol do estado do Rio Grande do $\mathrm{Su}$ ], vermelho com branco. O pessoal vende, vão lá na praça vender, no calçadão, na feira. Vendem as coisas e entra dinheiro para eles. Eu não sei, nunca peguei dinheiro e nada, mas o dinheiro que entra eles compram coisas para os usuários. (Ent. 8)

Portanto, como foi evidenciado na colocação do Ent. 8, em alguns momentos, os trabalhos confeccionados no interior das oficinas terapêuticas surgem como meio de aquisição financeira. Essa dinâmica é rica em dois sentidos, primeiro que a partir do momento em que o indivíduo percebe a valia do seu produto pode adquirir recursos financeiros com este. E segundo pela oportunidade de interação com a sociedade, desmistificando assim o estigma e o preconceito com a loucura.

Deste modo, a partir do momento em que as limitações responsáveis por envolver a segregação são superadas, o sujeito trilha verdadeiramente por um caminho livre, recuperando sua subjetividade e identidade pessoal, assumindo sua cidadania:

Porque eu pude voltar a trabalhar, fiquei pouco tempo afastada do meu serviço, voltei a trabalhar, estou contribuindo para a sociedade, para mim, para a minha família eu acho assim que foi tudo. E ainda está sendo. (Ent. 7)

Nesta categoria temática são evidenciadas estratégias utilizadas pelo CAPS que contribuem com a reinserção psicossocial do louco. Entende-se que está reinserção está pautada numa compreensão do louco para além da linearidade da patologia, concebendo a loucura como um fenômeno amplificado e complexo. Neste contexto, as oficinas terapêuticas, a diversificação do cardápio do serviço e as atividades geradoras de renda, são estratégias fundamentais e intencionais na introdução do sujeito louco no mundo da vida.

\section{0 reposicionamento do usuário enquanto cidadão}

Torna-se relevante a temática em questão, pois tratar do reposicionamento do sujeito em sofrimento psíquico, buscando a sua cidadania, amplia as suas potencialidades. A partir do momento em que o serviço abre mão de criar expectativas em relação ao usuário, ou seja, quando ele desmitifica o rótulo que atribui ao se deparar com a loucura, a equipe pode ser surpreendida. Assim, o reposicionamento do indivíduo consiste na 


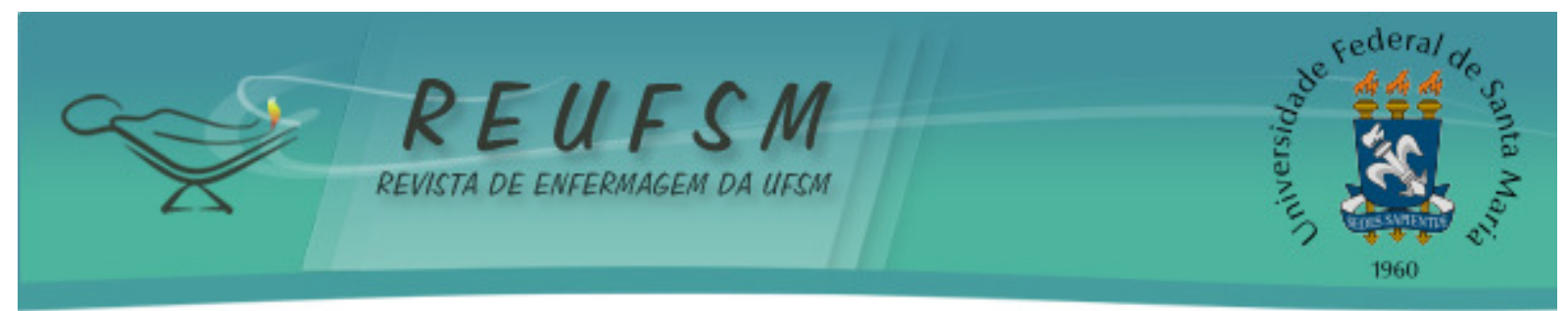

superação de limitações que envolvem a experiência com o sofrimento psíquico, indo mais além e encontrando-se com a liberdade.

No depoimento a seguir, o usuário reconhece essa transformação ocorrida em sua vida e faz um paralelo de sua situação quando não recebia atendimento no CAPS:

O serviço de saúde mental de Alegrete é como uma mãe. Ele é mais que uma mãe para qualquer um dos usuários. Porque são pessoas que apesar de todos os acontecimentos lutam com o coração, elas se importam conosco [...] São pessoas que Deus colocou no meu caminho, que estão me ajudando e investindo em mim. Acreditam no meu potencial, apesar de ter os meus defeitos [...] eu consegui serviço [...] me deram curso, quando eu preciso de dinheiro eles me ajudam, arrumam serviços para eu fazer, e assim tenho meu dinheiro [...]. Me ajudaram a me formar nos cursos, nos meus sonhos, e agora estão me ajudando no meu sonho que é ter a minha casa. (Ent. 1)

A inserção social dos indivíduos no contexto do mundo do trabalho se apresenta como que absolutamente a única possibilidade de ser aceito em sociedade. $\mathrm{E}$ com o passar do tempo, a modernidade responsabilizou-se por excluir uma parte cada vez maior de indivíduos "inaptos", expondo assim a precariedade dos laços sociais, bem como contribuindo para a segregação e exclusão. ${ }^{15}$

Eu ensino para eles pintura, costura, eu ensino o que eu aprendi, nem que seja um pouco, eu passo para eles tudo que eu sei. (Ent. 3)

Assim, como se percebe na verbalização acima, o sujeito em sofrimento psíquico reposicionou-se enquanto cidadão a partir do momento em que assumiu o papel de ensinar no interior de uma oficina terapêutica dentro do próprio serviço. Todavia, em outro momento surge uma maneira de o sujeito se sentir atuante em seu meio social, através da solidariedade repartida dentro do CAPS, pois através disso esse pode sentir-se influente:

Procuro ajudar eles, que tem menos condições psicológicas do que eu. E como sou mais são do que eles, psicologicamente, eu procuro ajudar, porque eles não têm noção nem nada, procuro ajudar, conversar com eles, dialogar com eles. (Ent. 9)

Esta categoria leva a compreensão de que o sujeito no CAPS é realocado enquanto um sujeito cidadão na sociedade que está submergido. A inclusão social pelo trabalho na sociedade capitalista compreende o cidadão como um detentor dos meios de produção, e ao produzir neste contexto social passa a integrá-la então.

\section{Nós críticos do tratamento em liberdade}

Pelo fato de o CAPS ter característica multiprofissional, torna-se necessário que esta equipe seja comprometida em trabalhar de forma interligada, ao mesmo tempo em que tenha afinidade com o campo da saúde mental, para que possa dispensar aos usuários um cuidado diferenciado e que realmente transforme-se em benefícios aos sujeitos em sofrimento psíquico.

Entretanto, na visão dos usuários do serviço, a equipe do CAPS demonstra-se estressada, assim como alguns usuários: 


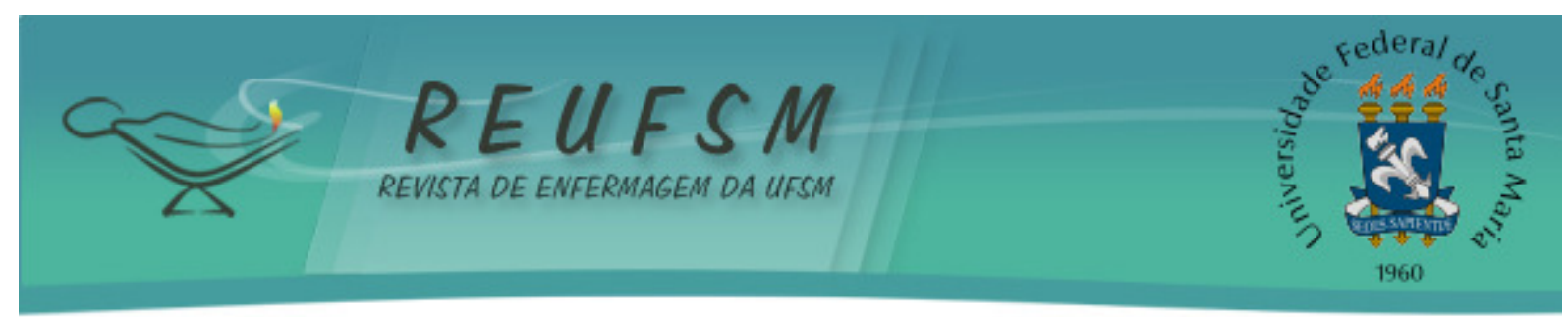

Aqui todo mundo é estressado, as pessoas, os outros meus companheiros são todos estressados, e estão como assim como eu, só estressado, qualquer outro tipo de pessoa se estressa. (Ent. 4)

Para que o trabalho em equipe seja fortalecido no interior dos CAPS, é necessário que as ações interdisciplinares se concretizem nas atividades pontuais destes serviços de saúde metal, por meio das reuniões de equipe, dos estudos de caso, e de tantos outras que gerem um espaço de trocas de intervenções coletivas e de saberes. Mais do que apartar práticas interdisciplinares de práticas multidisciplinares, é necessário evitar binarismos do que são práticas certas ou erradas. Uma prática multidisciplinar não se opõe as práticas interdisciplinares, mas vai ser construída e constituída a partir das práticas existentes no processo de trabalho. ${ }^{16}$

Outro fator contribuinte para o tensionamento das relações no interior do serviço é a falta de investimento da gestão municipal de saúde mental em apoiar o CAPS:

Eles não investem, tinham que investir mais no serviço da saúde mental, porque tem pessoas que estão aqui que são capacitadas em fazer as coisas. E ter mais chance para as pessoas portadoras de problemas psíquicos, que é o que falta, abrir mais oportunidades para eles, para eles poder se sentir gente só isso que falta. (Ent. 1)

Ainda, sabe-se sobre a importância das medicações na vida do indivíduo em sofrimento psíquico, pois servem como fator determinante para o seu bem-estar e para sua estabilidade. Todavia, com a mudança da gestão de saúde mental no município, houve alterações de prioridade na aquisição de medicações, e a partir de então começou a faltar medicamentos para os usuários, como se comprova na fala a seguir:

A pessoa que entrou, que está encarregada dessa parte, talvez achasse que estava sendo demais o que usavam de remédio e cortou pela metade ou mais até, eu acho que esse tipo de barreira que existe de pessoas achando assim que vai podando a medicação. (Ent. 7)

Sabe-se que a relação entre a sociedade e o fenômeno da loucura sempre foi muito conturbada, no sentido de que a loucura, no decorrer da história, foi vista sempre de maneira preconceituosa. Algumas pessoas têm dificuldade em aceitar o indivíduo em transtorno psíquico, muitos têm medo de serem agredidos, outros afirmam que "lugar de louco é no hospício" e outras colocações sem fundamento que só contribuem para aumentar esse estigma. A verdade é que o preconceito e o estigma ainda estão enraizados no meio social. ${ }^{17}$

Outro aspecto importante para a definição dos pontos responsáveis pelo tensionamento das relações dentro do CAPS é o fato da grande demanda de pessoas que chegam ao serviço em busca de atendimento, o que o torna superlotado e sendo assim, há uma grande dificuldade em marcar consultas. Com isso, é dada prioridade aos casos de urgência, e muitos usuários necessitam esperar mais tempo para serem atendidos:

Aqui é assim. Para a pessoa ser atendida é uma burocracia, às vezes atendem, procuram atender uma pessoa que está lá atrás da gente, que é prioridade. (Ent. 9)

Surge outro aspecto que concorre para os nós críticos do tratamento em liberdade: o fato do serviço contar com poucas atividades em seu âmbito. O CAPS poderia disponibilizar uma maior diversidade de oficinas e atividades: 


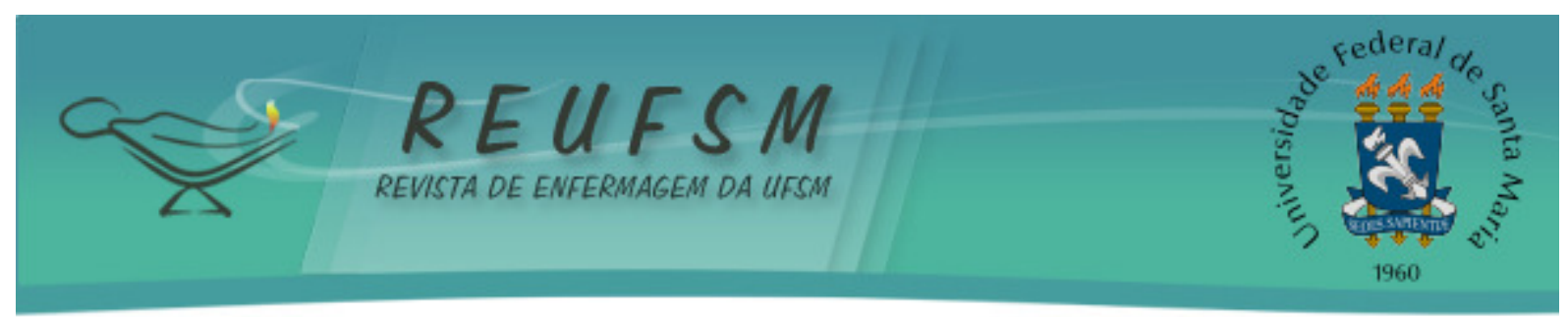

Aqui tem poucas atividades físicas, só pela manhã que é da aula de capoeira, faltam outras atividades. (Ent. 9)

A variedade de oficinas e atividades no CAPS poderá contribuir para a reabilitação psicossocial do usuário, tornando-o mais autônomo e empoderado.

Nesse sentido, este serviço é de extrema importância para a consolidação da reforma psiquiátrica brasileira, e tem requerido uma nova prática de ações, considerando, sobretudo o conjunto de atividades a que se propõe como parte integrante da rede de atenção psicossocial. ${ }^{16}$

E para que a atenção em saúde mental seja modificada ainda há muito a ser feito, sendo necessário o envolvimento de vários segmentos como a maior sensibilização dos poderes públicos e da sociedade; engajamento de instituições formadoras; reflexão da prática profissional nesse âmbito e o desenvolvimento de pesquisas que contribuam para a consolidação da reforma psiquiátrica. ${ }^{18}$

\section{CONSIDERAÇÕES FINAIS}

Este estudo apresenta contribuição para a área da saúde e para a enfermagem, pois aponta os tensionamentos e avanços do tratamento em liberdade, no contexto do CAPS de Alegrete, sob a visão dos usuários do serviço.

Foram identificadas estratégias que são empregadas pelo serviço e que servem de modelo para que outros CAPS também utilizem, e se aproximem assim dos sonhos possíveis almejados pela reestruturação da assistência psiquiátrica.

Por meio da análise dos dados, surgiram quatro temáticas anteriormente expostas, as quais revelaram que o serviço do município de Alegrete está exercendo seu papel de facilitador na vida do usuário.

A maioria dos usuários entrevistados relataram que percebem a diferença entre o atendimento que recebiam nos hospitais psiquiátricos, e a assistência em saúde mental que recebem no CAPS. E consequentemente, sentem-se fortalecidos para estarem inseridos e atuantes na sociedade.

Acredita-se que um marcador importante de efetividade da atenção psicossocial no CAPS é a possibilidade de o serviço tornar-se um promotor da reabilitação psicossocial dos usuários, contemplando as diversas esferas da vida: casa, lazer, trabalho, como se percebe no CAPS de Alegrete.

A reabilitação psicossocial é a chave para que o usuário reconquiste a sua cidadania. Através da retomada de suas habilidades, esse se tornará mais fortalecido e preparado para conviver com os demais em seu território social. Sendo assim, a partir desse momento tornase fundamental o aumento do poder contratual dos indivíduos, que é o poder de trocas, através do estreitamento dos vínculos. 0 usuário deixa de ser sozinho e limitado em suas relações, e passa a trilhar por um caminho mais igualitário e em direção à liberdade.

Em relação aos pontos de tensionamentos identificados, surge o desafio para que sejam trabalhadas e fortalecidas as questões de investimento da gestão de saúde mental no CAPS. Outro desafio importante a ser vencido, é o desenvolvimento do trabalho em equipe de maneira integrada e efetiva, ajustando os laços entre os diferentes campos profissionais, para que possam estar afinados com os pressupostos da reforma psiquiátrica, a fim de qualificar ainda mais a assistência em saúde mental.

\section{REFERÊNCIAS}

1. Ministério da Saúde (BR). Portaria/GM no 336, de 19 de fevereiro de 2002. Define e estabelece diretrizes para o funcionamento dos Centros de Atenção Psicossocial. Brasília (DF): Ministério da Saúde, Gabinete do Ministro; 2002.

2. Ministério da Saúde (BR). CAPS - Perguntas e respostas. Brasília (DF); 2002. 


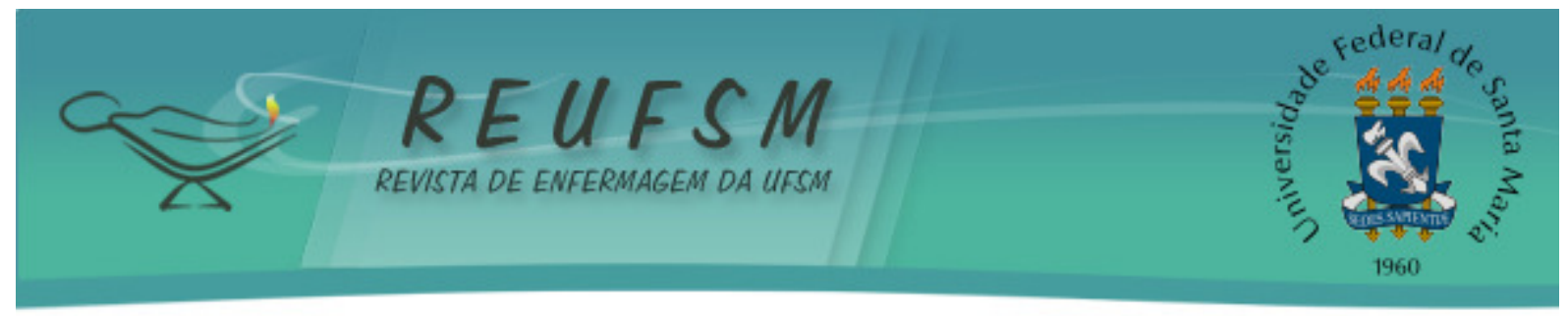

3. Nasi C, Schneider JF. O Centro de Atenção Psicossocial no cotidiano dos seus usuários. Rev Esc Enferm USP. 2011;45(5):1157-63.

4. Saraceno B. Reabilitação psicossocial: uma estratégia para a passagem do milênio. In: Pitta AMF, organizador. Reabilitação psicossocial no Brasil. São Paulo: Hucitec; 1996. p. 13-8.

5. Minayo MCS. O desafio do conhecimento: pesquisa qualitativa em saúde. 2a ed. São Paulo: Hucitec; 2010.

6. Ministério da Saúde (BR). Resolução CNS no 196, de 10 de outubro de 1996. Aprova diretrizes e normas regulamentadoras de pesquisas envolvendo seres humanos. Brasília (DF): Conselho Nacional de Saúde; 1996.

7. Ministério da Saúde (BR). Secretaria de Atenção à Saúde. Saúde mental. Brasília (DF): Ministério da Saúde; 2013. (Cadernos de atenção básica; 34).

8. Amarante P. Saúde mental e atenção psicossocial. São Paulo: FIOCRUZ; 2007.

9. Jorge MSB, Randemark NFR, Queiroz MVO, Ruiz EM. Reabilitação psicossocial: visão da equipe de saúde mental. Rev Bras Enferm. 2006;59(6):734-9.

10. Mello R, Furegato ARF. Representações de usuários, familiares e profissionais acerca do CAPS. Esc Anna Nery Rev Enferm. 2008 set;12(3):457-64.

11. Ministério da Saúde (BR). Saúde mental no SUS: os centros de atenção psicossocial. Brasília (DF); 2004.

12 Mielke FB, Olschowsky A, Pinho LB, Wetzel C, Kantorski LP. Avaliação qualitativa da relação de atores sociais com a loucura em um serviço substitutivo de saúde mental. Rev Bras Enferm. 2012 maio-jun;65(3):501-7.

13 Saraceno B. Libertando identidades: da reabilitação psicossocial à cidadania possível. 2은 ed. Rio de Janeiro: Te Corá; 2001.

14 Botti NCL. Oficinas em saúde mental: história e função [doutorado]. Ribeirão Preto (SP): Universidade de São Paulo; 2004. $244 \mathrm{f}$.

15 Pitta AMF. O que é reabilitação psicossocial no Brasil, hoje? In: Pitta AMF, organizador. Reabilitação psicossocial no Brasil. São Paulo: Hucitec; 1996. p. 19-26.

16 Meirelles MCP, Kantorski LP, Hypolito AM. Reflexões sobre a interdisciplinaridade no processo de trabalho de centros de atenção psicossocial. Rev Enferm UFSM. 2011; [acesso em 2014 mai 14];1(2):282-9. Disponível em: http://cascavel.ufsm.br/revistas/ojs2.2.2/index.php/reufsm/article/view/2551/1689.

17 Kantorski LP. CAPSUL - Avaliação dos CAPS da Região Sul do Brasil: relatório. Pelotas (RS); 2007. 437 p.

18 Souza AR, Silva ARV, Bezerra CP, Braga VAB. A inserção do enfermeiro no Centro de Apoio Psicossocial (CAPS): refletindo sobre a prática profissional. Rev RENE. 2008;9(1):154-61.

Data de recebimento: $13 / 05 / 2013$

Data de aceite: 14/01/2014

Contato com autor responsável: Ariane da Cruz Guedes

Endereço: Rua: Marechal Deodoro, 1087. Apto. 302. Centro. CEP: 96020-220. Pelotas-RS.

E-mail: arianecguedes@gmail.com 